\title{
Process Systems Analysis of Renewables-Based Chemicals Production
}

\section{Alternative Feedstocks Program}

The U.S. Department of Energy (DOE) Alternative Feedstocks (AF) program is forging new links between the agricultural community and the chemicals industry through support of research and development ( $R \& D)$ that uses "green" feedstocks to manufacture high-volume chemical building blocks. Industrial commercialization of such processes would stimulate the agricultural sector by increasing the demand for agricultural and forestry commodities. New alternatives for American industry may lie in the nation's forests and fields.

\section{Process Systems Analysis}

The initiation of new engineering projects results from the recognition of human necessities and societal desires. Processing systems developed to provide for such needs must pass analyses of technological and economic feasibility under prevailing institutional, social, regulatory, and political conditions. The AF program's Process Systems Analysis (PSA) project provides the means to carry-out the rational screening, evaluation, and selection of research and development projects, not only with regard to economic efficiency, but also to social equity, quality of life, and environmental preservation. In addition, once projects have been selected for further development, the PSA task provides decision-makers with the analyses essential to focus $R \& D$ activities towards the critical, process-specific economic, environmental, safety, and reliability issues. Thus, the PSA project strives to insure that the AF program's $R \& D$ does the right things and does things right.

\section{Project Screening}

There is once again considerable interest in producing chemicals from renewable resources. This renewed interest is justified by the many technological advances that can make these processes economically competitive. However, numerous technical improvements will be necessary to fully realize the potential global benefits of biobased processes. Amidst all the hopes for this technology lies a great deal of uncertainty. Careful attention to the sources of these uncertainties is vital to any process that attempts to sort out opportunities. An efficient method to classify products and processes as to their potential for near-, mid-, or long-term application was developed by the PSA project and is used to aid in the identification of promising opportunities for research, development, and commercialization.

The iterative, progressively-detailed technology screening approach developed consists of five phases. Initially, candidates are selected into a portfolio based on their ability to meet criteria setup to be consistent with the AF program's mission. The candidates are periodically ranked with respect to a simple economic criterion based on the market value, the price of the primary feedstock material, and the product yield. Simple comparisons are then made between producing the product via the most competitive conventional route and via the proposed biobased route. Next, qualitative information is gathered from industry experts on the advantages and disadvantages of each product with respect to energy impacts, environmental quality, and economic competitiveness.

In the last phase of the screening methodology, preliminary engineering economic evaluations are performed for the most promising candidates to assess the potential process profitability. The information generated in this analysis, combined with project-specific industrial interest or cost-sharing commitment, is used to select projects for funding and further research, development, and demonstration.

\section{DOE Laboratory Consortium \\ Argonne National Laboratory Idaho National Engineering Laboratory National Renewable Energy Laboratory Oak Ridge National Laboratory Pacific Northwest Laboratory}

\section{Selected Examples of Collaborators}

Environmental Protection Agency Risk Reduction Laboratory Michigan Biotechnology Institute National Corn Growers Association Pioneer Hi-Bred International, Inc. 


\section{Process Design}

The effective planning of research aimed at gathering design data for a new process demands an understanding of economic, as well as technical, aspects of the process. If economic factors affecting the optimal choice of process conditions are not appreciated, laboratory data may be obtained for circumstances unrelated to those of a viable process. The main tasks of the design engineer at the research stage include devising practical and economical means of performing the operations proposed on the commercial scale, and ensuring that reliable data for scale-up and plant design are obtained for the practical circumstances envisaged.

Economic models of proposed processing systems are constructed once a project has been selected for further research and development. The complexity of these models vary with projects and depend in part on the availability of design information.

The primary purpose of the economic models is to identify the elements of the process that most strongly affect the safety, operability, reliability, and profitability. The ultimate goal is to specify the most economical and effective practical procedures and processing plant required to produce the product from a renewable resource on a commercial scale. This is generally achieved only after many iterations exploring the detailed implications of alternative, technically feasible, processing routes.

\section{The Decision-Analysis Process}

The decision-analysis process for engineering and $\mathrm{R} \& \mathrm{D}$ project development is iterative in nature and includes the following basic steps:

- Problem definition

- Identifying criteria, objectives, and alternatives

For more information on this technology or the DOE Alternative Feedstocks program, contact:

\section{Ron Landucci}

Process Systems Analysis Project

National Renewable Energy

Laboratory

1617 Cole Boulevard

Golden CO 80401

Phone: (303) 275-4416

Fax: (303) 275-4452

Internet: landuccr@tcplink.nrel.gov

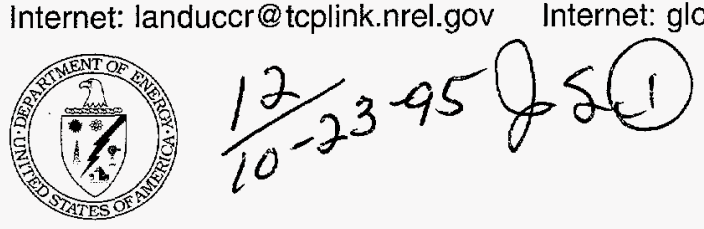

This document was produced for the U.S. Department of Energy (DOE) by the National Renewable Energy Laboratory, a DOE national laboratory.

$D O E / G O-10095-210$

DE95013109
- Characterizing and modeling the processing systems

- Evaluating and choosing the best alternative

- Implementing the chosen alternative.

Definitive problem statements are made with the understanding of the unique AF program goals. Only then can realistic objectives and constraints be set for initiating the new project. The generation of alternative processes to meet the criteria for a proposed project involves the inductive process of synthesizing solutions to the problem. In general, the conceptual models of proposed systems are analyzed and evaluated with regard to the characteristics of the relevant parameters and variables, and, if necessary, are modified and developed to optimize their performance with respect to cost. Although the quantitative relationships between performance and cost are useful in making a choice between alternative plans, they are not the only basis for comparison because they often do not include intangible factors, social benefits and costs that cannot be readily quantified.

\section{Tools and Methodologies}

The approaches and principles followed by the $\mathrm{AF}$ program PSA project are in adherence with those adopted by the AACE International. Where appropriate, the adopted methodologies have been modified to account for the unique nature of the burgeoning renewable resource-based chemical industry. Commercially available computer-based analysis tools are chosen for their robustness and used when required. These tools include the ASPEN-PLUS chemical process simulator and the ICARUS Questimate and IPE equipment costing programs. When necessary, new tools and methodologies have been developed to improve the analytical efficiency of the PSA project.
Gloria Kulesa

Alternative Feedstocks Program

U.S. Department of Energy

EE-233, 5F-059

1000 Independence Avenue, SW

Washington, DC 20585

Phone: (202) 586-8091

Fax: (202) 586-3180

Internet: gloria.kulesa@hq.doe.gov 


\section{DISCLAIMER}

This report was prepared as an account of work sponsored by an agency of the United States Government. Neither the United States Government nor any agency thereof, nor any of their employees, makes any warranty, express or implied, or assumes any legal liability or responsibility for the accuracy, completeness, or usefulness of any information, apparatus, product, or process disclosed, or represents that its use would not infringe privately owned rights. Reference herein to any specific commercial product, process, or service by trade name, trademark, manufacturer, or otherwise does not necessarily constitute or imply its endorsement, recommendation, or favoring by the United States Government or any agency thereof. The views and opinions of authors expressed herein do not necessarily state or reflect those of the United States Government or any agency thereof. 


\section{DISCLAIMER}

Portions of this document may be illegible in electronic image products. Images are produced from the best available original document. 